$\mathrm{Mn}^{8+}\left(d^{4}\right)$ in the latter had only one and two unpaired electrons respectively ${ }^{2}$. This distribution satisfies the requirement of $\mathrm{Mn}^{\text {s+ }}$ ions at octahedral sites which in virtue of one empty $d$-orbital would take part in $d s p^{2}$ square bonds to produce the appropriate distortion of each elementary octahedron $(c / a>1)$. Furthermore, the cations at tetrahedral sites which have two empty $d$-orbitals would seem to form $d^{2} s p$ hybrid (irregular tetrahedral) bonds ${ }^{2}$. This is also in accord with the geometrical requirements where in both the substances the $\mathrm{MeO}_{4}$ tetrahedra are also distorted and can be described as tetragonal sphenoids $^{6}$ with $\alpha_{1}=\alpha_{2}=102^{\circ} 30^{\prime}$ and $\beta=113^{\circ} 34^{\prime}$, the central cation being equidistant from oxygen ions.

The above electronic distribution of $3 d$ electrons in the tetrahedrally situated cations, which seems to be in violation of Hund's rule, can also be justified from the point of view of crystal field theory.

According to this approsch ${ }^{5}$, the $\left(t_{2} g\right)^{3}\left(e_{g}\right)$ configuration of octahedrally situated $\mathrm{Mn}^{3+}\left(d^{4}\right)$ ions, having degeneracy with respect to $e_{g}$ orbitals, gives rise to a Jahn-Teller distortion whereby $c / a>1$. This is in agreement with observation. However, configurations with highest permissible multiplicity for tetrahedral cations are $(e)^{2}\left(t_{2}\right)^{3}$ for $\mathrm{Mn}^{2}+$ in $\mathrm{Mn}^{2+}\left[\mathrm{Mn}_{2}^{8+}\right] \mathrm{O}_{4}$ and $(e)^{2}\left(t_{2}\right)^{2}$ for $\mathrm{Mn}^{8+}$ in $\gamma-\mathrm{Mn}_{8}^{8+} \mathrm{O}_{3}$. For the former the Jahn-Teller distortion is zero and for the latter $c / a<1$. In fact, this distortion of tetrahedral groups will oppose that of octahedral groups. This would conflict with the observed situation where in both the substances $c / a=1 \cdot 16$. A distortion of the tetrahedral group consistent with $c / a>1$ is expected from a configuration where there is, in these ions, a single electron in the $t_{2}$ orbital (in effect $T_{2}$ state). Thus the modified configuration for such ions would be $(e)^{4}\left(t_{2}\right)$ for $d^{5}$ and $(e)^{3}\left(t_{2}\right)$ for $d^{4}$. This distribution is in agreement with the total spin values derived from the magnetic data.

Actually, the distortion of $M e \mathrm{O}_{6}$ octahedra to give $c / a>1$ and the corresponding distortion of $\mathrm{MeO}_{4}$ tetrahedra amounts to the production of a strong crystal field which would favour the low spin-states.

It is expected that a molecular orbital approach which takes into account the essential features of the Jahn-Teller effects would lead to a more consistent picture.

I am grateful to Prof. M. H. L. Pryce for discussions.

H. H. Wills Physics Laboratory,

K. P. Sinha*

University of Bristol. Jan. 20.

* Permanent address: National Chemical Laboratory, Poona 8, India.

${ }^{1}$ Goodenough, J. B., and Loeb, A. L., Phys. Rev., 98, 391 (1955).

${ }^{2}$ Sinha, K. P., and Sinha, A. P. B., J. Phys. Chem., 61, 758 (1957)

${ }^{3}$ Sinha, A. P. B., Sanjana, N. R., and Biswas, A. B., Acta Cryst., 10, 439 (1957).

'Obik, U., and Pryce, M. H. L., Proc. Roy. Soc., A, 288, 425 (1957).

'Dunitz, J. D., and_Orgel, L. E., J. Phys. Chem. Solids, 3, 20, 318 $(1957)$

${ }^{6}$ Lachman, F., J. Chem. Phys., 22, 1459 (1954).

\section{Murexide Test in Paper Chromatography}

MrCHEL ${ }^{1}$ found that the purines on a moist filter paper, when treated with chlorine gas for $3 \mathrm{~min}$., dried at $80-90^{\circ} \mathrm{C}$. and left in an ammonia atmosphere for a few minutes form compounds which are detectable by their fluorescence in ultre-violet light. A true murexide test, with development of a pink coloration, can be carried out without using chlorine directly, by lightly spraying the paper first with a 10 per cent solution of chloramine $T$ (B.P.) and then with $N$ hydrochloric acid, followed by heating it in a steam-oven $\left(96-98^{\circ} \mathrm{C}\right.$.) until there is no smell of chlorine. The dried peper is then passed slowly over the open mouth of a bottle of concentrated ammonia and heated in the steam-oven for 5-10 min., when the purines will show up as pink spots. It is sometimes necessary to repeat the ammonia treatment and subsequent heating to make the spot visible. Morgan ${ }^{2}$ used chloramine $T$ as an oxidizing agent for detection of caffeine in the conventional way by the murexide test.

This method will detect uric acid, $\operatorname{caffein} \theta$, theophylline, theobromine and xanthine in approximately microgram quantities of $1 \cdot 5,18,38,1$ and 7 respectively. When viewed in ultra-violet light the spots show violet fluorescence, and the minimum detectable quantities are reduced to approximately one-third of those quoted above.

We wish to thank the Indian Tea Association for permission to publish this communication.

N. B. Chanda

S. Chakraborty

Tocklai Experimental Station,

Indian Tea Association,

Cinnamara, Assam.

1 Michel, J., Natumvissenschaften, 40, 390 (1953). 2 Morgan, C. E., and Opolonick, N., Indust. and Eng. Chem., 17, No. 8,

\section{Acidity of Sprays used in detecting Ketohexoses on Paper Chromatograms}

SEVERAL spray reagents are available for the specific detection of ketoses and ketose-containing sugars on paper chromatograms. Probably the most widely used are resorcinol and naphthoresorcinol, originally prepared as sprays in $2 N$ hydrochloric acid by Forsyth ${ }^{1}$. Afterwards, Partridge ${ }^{2}$ replaced the hydrochloric acid with trichloracetic acid in order to minimize attack on the filter paper. Heyrovsky ${ }^{3}$ has recently reported that $\beta$-indolyl acetic acid in trichloracetic acid is also a very sensitive ketose-specific reagent. In work in this laboratory on two fructosecontaining disaccharides it has been found that all three of the above reagents, when prepared in trichloracetic acid, failed completely to detect these sugars on paper chromatograms. When the trichloracetic acid was replaced with $2 N$ hydrochloric acid strong positive tests were obtained. The results are listed in Table 1.

Disaccharide $A$ was obtained from red clover (Trifolium pratense) and yielded fructose only on hydrolysis. Disaccharide $B$ was isolated from cultures of Streptococcus bovis ${ }^{4}$ and yielded both glucose and fructose on hydrolysis. Both sugars were somewhat resistant to acid hydrolysis and required $4 \mathrm{hr}$. at $100^{\circ}$ in $1.5 \mathrm{~N}$ sulphuric acid for complete hydrolysis. The two disaccharides were applied to

Table 1

\begin{tabular}{|c|c|c|c|}
\hline Reagent & Acid & $\underset{A}{\text { Disaccharide }}$ & $\underset{B}{\operatorname{Disacch}}$ \\
\hline $\begin{array}{l}\text { Resorcinol } \\
\text { Naphtho- } \\
\text { resorcinol } \\
\beta \text {-Indoly]- } \\
\text { acetic acid }\end{array}$ & $\begin{array}{l}\text { Trichloracetic } \\
2 N \text { hydrochloric } \\
\text { Trichloracetic } \\
2 N \text { hydrochloric } \\
\text { Trichloracetic } \\
2 N \text { hydrochloric }\end{array}$ & $\begin{array}{c}\text { nil } \\
\text { bright red } \\
\text { nil } \\
\text { deep red } \\
\text { nil } \\
\text { strong violet }\end{array}$ & $\begin{array}{c}\text { nil } \\
\text { bright red } \\
\text { nil } \\
\text { deep red } \\
\text { nil } \\
\text { strong violet }\end{array}$ \\
\hline
\end{tabular}

